\title{
Study on the Prevalence of Depression and Anxiety among Diabetes Mellites Patients in Tertiary Care Hospital- A Prospective Cross-sectional Study
}

\author{
Pem Tamang* \\ Department of Pharmacy Practice, Sri Venkateshwara College of Pharmacy, RVS Nagar, Chittoor, Andra Pradesh, INDIA.
}

\begin{abstract}
Background: Diabetes mellitus is one of the most predominant, chronic disease afflicting globally with its amplifying burden. The association of diabetes with psychological disorders exists with depression and anxiety being the most common, often remains undiagnosed or unidentified eventually leading to a decline in functional abilities and self-care, worsening the health profile of the patients and contributing to both morbidity and mortality. This study explores the association of psychiatric problems with diabetes mellitus and their related risk factors. Objectives: To investigate the association and the prevalence of psychiatric disorders (depression and anxiety) among diabetic patients and access their associated risk factors. Methods: A prospective cross-sectional study was conducted for six months in 105 diabetic patients from the outpatient department. Hospital Anxiety and Depression Scale (HADS) was used to evaluate the symptoms of anxiety and depression. Data were analyzed using Statistical Package for the Social Sciences (SPSS) version 25.0. Results: Overall 53 (50.5\%) were observed with the symptoms of anxiety while 45 (42.9\%) with symptoms of depression respectively. The prevalence of marked anxiety and depression was observed higher in a female. Anxiety and depression were also common among participants with moderate social support. Anxiety and depression were greater among patient who were illiterate $(O R=1.50,95 \%$ $\mathrm{Cl}$ 0.92-5.38), unemployed (OR=7.50,95\% Cl 1.29-43.61) with low income ( $\mathrm{PR}=3.09$ 95\% Cl 0.92-10.36) and who were retired $(\mathrm{OR}=6.00,95 \% \mathrm{Cl} 0.81-44.35)$. Conclusion: The result showed a high prevalence of depression and anxiety among female than in the male. Most of the patients developed moderate or severe anxiety and depression. Various factors such as low income, age, low education, unemployed, uncontrolled diabetes were associated with anxiety and depression. Awareness programs and health education should be conducted. Counseling and appropriate medication should be initiated to reduce future complications.
\end{abstract}

Key words: Diabetes, Anxiety, Depression, Risk factors, Hospital Anxiety and Depression Scale, Hypothalamus Pituitary Adrenal axis, Sympathetic Nervous System.

\section{INTRODUCTION}

Diabetes was found to be one of four predominant Non-Communicable Diseases (NCDs) due to its amplifying global burden. ${ }^{1}$ Diabetes is considered to be the seventh leading cause of death, with a steady increase in prevalence from $4.7 \%$ in 1980 to $8.7 \%$ in 2014. An estimate of 1.6 million deaths was supposedly reported due to diabetes in 2016. ${ }^{2}$ Most of the diabetic pollution belonged to low-income or middle-income countries with the highest prevalence among people between 40-59 age group. ${ }^{3}$ With a substantial increase in the burden of diabetes over decades in India, it was estimated to have 72 million cases in 2017 and currently representing $49 \%$ of the total burden of diabetes globally, it is expected to bifold to 134 million by 2025 making it a serious health concern. It was known that $2.6 \%$ of women were at higher risk than the men with 3.7\% risk respectively. Additionally, it is stated that one in every four individuals under the age of 25 years had adult-onset of diabetes. ${ }^{4}$

Depression is the most common mental health problem in diabetic patients and often accompanied by anxiety disorders, it was observed that the prevalence of these psychological distress was higher among patients with chronic comorbidities that ranges between 16-50\%. ${ }^{5-7}$ Psychological disorders like anxiety and depression occurs
DOI: 10.5530/ijopp.13.2.18

Address for correspondence: Pem Tamang, M.Pharm Department of Pharmacy Practice, Sri Venkateshwara College of Pharmacy, RVS Nagar, Chittoor-517127, Andra Pradesh, INDIA.

Phone no: +917627091071 Email Id: pemtamang393@ gmail.com

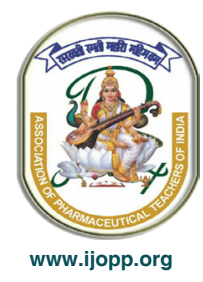


in every 1 of 4 adults with DM1 and DM2 but often remain unidentified and undiagnosed which results in failure to provide appropriate treatment. ${ }^{8} 38$ million people in India were reportedly affected by depression with the prevalence of $1.9 \%$ in men and $3.5 \%$ in women. ${ }^{9}$ Anxiety prevails in $40 \%$ of patients with DM1 and DM2. The incidence rate of depression was found to be three times higher in DM1 diabetic patient and two times higher in DM2. The occurrence of depression and anxiety in diabetic patients results in non-compliance to medical treatment, increased risk of comorbidities, interference in daily activities, increased morbidity and mortality and decrease quality of life, worsening the prognosis of the disease. $^{10,11}$

The objective of the research is to assess the prevalence of psychological disorders such as; depression and anxiety among diabetic patients and to evaluate association of socio-demographic and other clinical factors in a health care setting. It provides a frame of reference to examine these association and produce theory-driven documentation using Hospital Anxiety and Depression Scale (HADS).

Depression and anxiety may result from neurochemical changes and environmental factors which activate common pathway that develop depression and anxiety in diabetic patients, affecting health outcome and decline functional abilities and self-care. Activation and alteration of stress triggers Hypothalamus Pituitary Adrenal axis (HPA-axis) and Sympathetic Nervous System (SNS) resulting in increased production of cortisol in adrenal cortex and production of adrenalin and noradrenaline in adrenal medulla, these counter-regulatory hormones increase glucose levels in the blood via catabolic processes like ketosis. ${ }^{12}$ Conversely, chronic stress release, cortisol and other hormones results in behavioral alteration that activate fear system which results in development of anxiety. ${ }^{13}$ Hypercortisolemia and prolong activation of SNS which further aids insulin resistance which manifest metabolic syndrome such as such as weight gain, visceral adiposity, dyslipidemia, hypertension, overeating and decreased interest in self-care, which can worsen the symptoms of diabetes. ${ }^{13,14}$ Persistent stress also produces an increased production of inflammatory cytokines which interconnect with beta-cell resulting in the insulin resistance as seen in DM $2 .{ }^{15}$ It appears that the DM1 diabetes, anxiety and depression has similar pathophysiological pathway to that of DM2. The biological link exists between DM1 with depression and anxiety involves; association between autoimmune disease and increase in cytokines production, neurogenesis and neurotransmitter metabolism due to lack of insulin which enhance activity of HPA-axis and chronic hyperglycemia. ${ }^{16}$

\section{MATERIALS AND METHODS \\ Study Design and Study setting}

A prospective cross-sectional study was conducted for a period of six months from February 2019 to July 2019 at Lifeline Multispeciality Hospital, Chittoor, Andhra Pradesh, India in the outpatient department. The study was approved by the Institutional Ethical Committee (IEC/RVSIMS/2019/07). A total of 105 male and female patients were selected by a random systematic sampling method. Informed consents were obtained from the participants who were agreed to participate in the study.

\section{Selection of Participants}

\section{Inclusion and Exclusion Criteria}

Sampling method was used to carry out the study among diabetic patients attending the Lifeline hospital was based on the following inclusion and exclusion criteria.

\section{Inclusion criteria}

- Involves patients with diabetes for at least one year.

- Patients of either sex above 20 years of age who understand the questions in order to complete forms and questionnaire.

- Patients who are willing to participate in the study and are capable of independent communication and giving informed verbal consent.

\section{Exclusion criteria}

- The patients with gestational diabetes and individuals without blood test reports (FBS) in past 3 months.

- Patients with diagnosis of depression and anxiety or any other mental illness or known history of severe or long-term psychiatric illness, history of taking antidepressant medication were excluded from the study.

\section{Data collection}

The self-administered questionnaire is divided into three sections, the first section contains the socio-demographic details of each individual patients such as gender, age, marital status, education level, monthly income, social support and employment status. The second section includes the clinical factors which involves duration of diabetes, disease control. The third section assess anxiety and depression among diabetic patients with the use of Hospital Anxiety and Depression Scale (HADS). The 
HADS incorporates 14 questions, 7 of which measure anxiety level (A) and other 7 measures depression level (D). HADS consist of four possible options which investigate an emotional state of the patient and the participants must choose one of the options that precisely reflects their mental status.

The total score provides subscale scores of anxiety and depression which range between 0-21 individually, though the score of anxiety and depression is summed and evaluated separately. A score of $0-7$ shows that the patient is normal, a score between 8-10 means mild distress and a score between 11-21 means severe distress as shown in the table below. HADS uses a score of more than 8 as a "cut-off score" which means a score below 8 indicates that the person is normal and a score beyond 8 means that there is anxiety and depression. ${ }^{17,18}$

\section{Analysis of Data}

Data entry and analyses were carried out using the Statistical Package for the Social Sciences (SPSS) version 25.0, IBM. The associated variables (demographic and clinical) with anxiety and depression were assessed using chi-square or $t$-test as appropriate. $P<0.05$ was considered statistically significant. Multivariate analysis was carried out using logistic regression. Results of logistic regression are expressed as OR with 95\% confidence interval.

\section{RESULTS}

\section{Demographic and clinical characteristic of diabetic patients}

The sociodemographic and clinical characteristic of the study subjects are shown in Table 1 . The mean age of the participants was 50.29 with Standard Deviation (SD) of \pm 10.085 years. Of 105 subjects, $57.1 \%$ were male and $42.9 \%$ were female. $95.2 \%$ of the participant were married with only $4.8 \%$ unmarried. Most $28.6 \%$ of the participants were illiterate with the earnings of 5,00010,000 per month. Majority of the subjects $82.9 \%$ had diabetes for the duration of $1-10$ years. $37.1 \%$ were an insulin user. $61.0 \%$ of the participants had a moderate support from their family. Out of all the study, $57.1 \%$ had a good glycemic control $\left(\mathrm{HbA}_{1 \mathrm{c}}<7 \%\right)$ with $44.8 \%$ who had $<3$ complication or comorbidities.

\section{Prevalence of anxiety and depression}

The finding of the study reveals that of 105 participants, $53(50.5 \%)$ were observed with the symptoms of anxiety while $45(42.9 \%)$ with symptoms of depression as shown in Table 2. The distress was at the borderline in $32(30.5 \%)$
Table 1: Demographic and clinical characteristic of diabetic patients $(n=105)$.

\begin{tabular}{|c|c|}
\hline Characteristic & Frequencies (\%) \\
\hline Age (in years) & $50.29 \pm 10.086$ \\
\hline $\begin{array}{l}\text { Gender, } \mathbf{n}(\%) \\
\text { Male } \\
\text { Female }\end{array}$ & $\begin{array}{l}60(57.1) \\
45(42.9)\end{array}$ \\
\hline $\begin{array}{l}\text { Marital Status, n (\%) } \\
\text { Married } \\
\text { Unmarried }\end{array}$ & $\begin{array}{l}100(95.2) \\
5(4.8)\end{array}$ \\
\hline $\begin{array}{l}\text { Education, n (\%) } \\
\text { Illiterate } \\
\text { Primary school } \\
\text { ntermediate } \\
\text { High school } \\
\text { Diploma } \\
\text { Graduate }\end{array}$ & $\begin{array}{l}30(28.6) \\
20(19.0) \\
21(20.0) \\
14(13.3) \\
6(5.7) \\
14(13.3)\end{array}$ \\
\hline $\begin{array}{l}\text { Occupation, } \mathbf{n}(\%) \\
\text { Unemployed/ house wife } \\
\text { Employed } \\
\text { Retired } \\
\text { Other }\end{array}$ & $\begin{array}{l}35(33.3) \\
50(47.6) \\
12(11.4) \\
8(7.6)\end{array}$ \\
\hline $\begin{array}{l}\text { Income per month, } \mathbf{n}(\%) \\
<500 \\
5,000-10,000 \\
10,000-15,000 \\
>15000\end{array}$ & $\begin{array}{l}28(26.7) \\
33(31.4) \\
25(23.8) \\
19(18.1)\end{array}$ \\
\hline $\begin{array}{l}\text { Social support, } \mathbf{n}(\%) \\
\text { High } \\
\text { Moderate } \\
\text { Low }\end{array}$ & $\begin{array}{l}30(28.6) \\
64(61.0) \\
11(10.5)\end{array}$ \\
\hline $\begin{array}{l}\text { Duration of diabetes in } \\
\text { years, } n(\%) \\
1-10 \\
10-20 \\
>20\end{array}$ & $\begin{array}{l}87(82.9) \\
15(14.3) \\
3(2.9)\end{array}$ \\
\hline $\begin{array}{l}\text { Insulin use, n (\%) } \\
\text { Yes } \\
\text { No }\end{array}$ & $\begin{array}{l}39(37.1) \\
66(62.9)\end{array}$ \\
\hline $\begin{array}{l}\mathbf{H b A}_{1 \mathrm{c}}(\%) \\
\text { Controlled (<7\%) } \\
\text { Uncontrolled }(>7 \%)\end{array}$ & $\begin{array}{l}60(57.1) \\
45(42.9)\end{array}$ \\
\hline $\begin{array}{l}\text { Control of diabetes, } \mathbf{n}(\%) \\
\text { Controlled } \\
\text { Not controlled }\end{array}$ & $\begin{array}{l}47(44.8) \\
58(55.2)\end{array}$ \\
\hline $\begin{array}{l}\text { No. of complication, } \mathbf{n}(\% \\
<3 \\
3 \\
>3\end{array}$ & $\begin{array}{l}50(44.8) \\
26(24.8) \\
29(27.6)\end{array}$ \\
\hline
\end{tabular}

subjects and abnormal in 21(20.0\%) participants. HADS shows the mean score of mild distress was 8.9 with SD of $\pm 0.9,15.5$ with S.D of \pm 2.9 for the severe distress and, 5.1 with S.D \pm 1.4 for normal score for anxiety. The mean score with mild distress was 8.9 with S.D \pm 0.80 , for severe distress the mean was 15.3 with S.D \pm 2.5 and the normal mean score was 5 with S.D \pm 2.9 for depression. The prevalence of marked anxiety and depression was higher in female as compared to male. 
Table 2: Prevalence of anxiety and depression among diabetic patients ( $n=105)$ according to the severity of disease measured by HADS.

\begin{tabular}{ccccccccc}
\multicolumn{3}{c}{ Anxiety } & \multicolumn{5}{c}{ Depression } \\
\hline Scale & $\begin{array}{c}\text { Avg } \\
\text { score, } \\
\text { mean, SD }\end{array}$ & $\begin{array}{c}\text { Total, } \\
\mathbf{n ~ ( \% )}\end{array}$ & $\begin{array}{c}\text { Female } \\
\mathbf{n}(\%)\end{array}$ & $\begin{array}{c}\text { Male } \\
\mathbf{n ~ ( \% )}\end{array}$ & $\begin{array}{c}\text { Avg } \\
\text { score, } \\
\text { mean, SD }\end{array}$ & $\begin{array}{c}\text { Total } \\
\mathbf{n}(\%)\end{array}$ & $\begin{array}{c}\text { Female } \\
\mathbf{n}(\%)\end{array}$ & $\begin{array}{c}\text { Male } \\
\mathbf{n}(\%)\end{array}$ \\
Normal & $5.1 \pm 1.4$ & 52 & 14 & 38 & $5.0 \pm 1.50$ & 60 & 15 & $45(75.0)$ \\
& & $(49.5)$ & $(31.1)$ & $(63.3)$ & & $(57.1)$ & $(33.3)$ & \\
Borderline & $8.9 \pm 0.9$ & 32 & 18 & 14 & $8.9 \pm 0.80$ & 28 & 18 & $10(16.7)$ \\
& & $(30.5)$ & $(40.0)$ & $(23.3)$ & & $(26.7)$ & $(40.0)$ & \\
Abnormal & $15.5 \pm 2.9$ & 21 & 13 & $8(13.4)$ & $15.3 \pm 2.5$ & 17 & 12 & $5(8.3)$ \\
& & $(20.0)$ & $(28.9)$ & & & $(16.2)$ & $(26.6)$ & \\
\hline
\end{tabular}

Table 3: Anxiety and depression status by demographic and clinical variables.

\begin{tabular}{|c|c|c|c|c|}
\hline \multirow[t]{2}{*}{ Characteristic } & \multicolumn{2}{|c|}{ Anxiety } & \multicolumn{2}{|c|}{ Depression } \\
\hline & Yes $(n=53)$ & No $(n=52)$ & Yes $(n=45)$ & No $(n=60)$ \\
\hline \multicolumn{5}{|l|}{ Age } \\
\hline $25-54$ & $35(66.1 \%)$ & $33(63.5 \%)$ & $21(46.7 \%)$ & $47(78.3 \%)$ \\
\hline $55-84$ & $18(33.9 \%)$ & $19(36.5 \%)$ & $24(53.3 \%)$ & $13(21.7 \%)$ \\
\hline \multicolumn{5}{|l|}{ Gender } \\
\hline Male & $22(41.5 \%)$ & $38(73.1 \%)$ & $15(33.3 \%)$ & $45(75 \%)$ \\
\hline Female & $31(58.5 \%)$ & $14(26.9 \%)$ & $30(66.7 \%)$ & $15(25 \%)$ \\
\hline \multicolumn{5}{|l|}{ Marital status } \\
\hline Married & $50(94.3 \%)$ & $50(96.2 \%)$ & $45(100 \%)$ & 55 (91.7\%) \\
\hline Unmarried & $3(5.7 \%)$ & $2(3.8 \%)$ & 0 & $5(8.3 \%)$ \\
\hline \multicolumn{5}{|l|}{ Education Level } \\
\hline Illiterate & $18(33.9 \%)$ & $12(23.1 \%)$ & $25(55.6 \%)$ & $5(8.3 \%)$ \\
\hline Primary school & $12(22.6 \%)$ & $8(15.4 \%)$ & $10(22.2 \%)$ & $10(16.7 \%)$ \\
\hline Intermediate & $10(18.9 \%)$ & $11(21.2 \%)$ & $7(15.6 \%)$ & $14(23.3 \%)$ \\
\hline High school & $3(5.7 \%)$ & $11(21.2 \%)$ & $1(2.2 \%)$ & $13(21.7 \%)$ \\
\hline Diploma & $3(5.7 \%)$ & $3(5.6 \%)$ & 0 & $6(10 \%)$ \\
\hline Graduate & $7(13.2 \%)$ & $7(13.5 \%)$ & $2(4.4 \%)$ & $12(20 \%)$ \\
\hline \multicolumn{5}{|l|}{ Occupation } \\
\hline Unemployed & $25(47.2 \%)$ & $10(19.2 \%)$ & $29(64.4 \%)$ & $6(10 \%)$ \\
\hline Employed & $22(41.5 \%)$ & $28(53.8 \%)$ & $6(13.3 \%)$ & $44(73.3 \%)$ \\
\hline Retired & $4(7.5 \%)$ & $8(15.4 \%)$ & $8(17.7 \%)$ & $4(6.7 \%)$ \\
\hline Others & $2(3.8 \%)$ & $6(11.5 \%)$ & $2(4.6 \%)$ & $6(10 \%)$ \\
\hline \multicolumn{5}{|l|}{ Income per month } \\
\hline$<5000$ & $18(33.9 \%)$ & $10(19.2 \%)$ & $25(55.6 \%)$ & $3(5 \%)$ \\
\hline $5,000-10,000$ & $17(32.1 \%)$ & $16(30.8 \%)$ & $15(33.3 \%)$ & $18(30 \%)$ \\
\hline $10,000-15,000$ & $11(20.8 \%)$ & $14(26.9 \%)$ & $3(6.7 \%)$ & $22(36.7 \%)$ \\
\hline$>15,000$ & $7(13.2 \%)$ & $12(23.1 \%)$ & $2(4.4 \%)$ & $17(28.3 \%)$ \\
\hline \multicolumn{5}{|l|}{ Duration } \\
\hline $1-10$ & $43(81.1 \%)$ & $44(84.6 \%)$ & $32(71.1 \%)$ & 55 (91.7\%) \\
\hline $10-20$ & $9(16.9 \%)$ & $6(11.5 \%)$ & $10(22.2 \%)$ & $5(8.3 \%)$ \\
\hline$>20$ & $1(2 \%)$ & $2(3.8 \%)$ & $3(6.7 \%)$ & 0 \\
\hline \multicolumn{5}{|l|}{ Insulin use } \\
\hline Yes & $21(39.6 \%)$ & $18(34.6 \%)$ & $20(44.4 \%)$ & $19(31.7 \%)$ \\
\hline No & $32(60.4 \%)$ & $34(65.4 \%)$ & $25(55.6 \%)$ & $41(68.3 \%)$ \\
\hline \multicolumn{5}{|l|}{ Social support } \\
\hline High & $16(30.2 \%)$ & $14(26.9 \%)$ & $10(22.2 \%)$ & $20(33.3 \%)$ \\
\hline Moderate & $29(54.7 \%)$ & $35(67.3 \%)$ & $25(55.6 \%)$ & $39(65.0 \%)$ \\
\hline Low & $8(15.1 \%)$ & $3(5.8 \%)$ & $10(22.2 \%)$ & $1(1.7 \%)$ \\
\hline \multicolumn{5}{|l|}{$\mathrm{HbA}_{1 \mathrm{c}}(\%)$} \\
\hline$<7 \%$ & $26(49.1 \%)$ & $34(65.4 \%)$ & $16(35.6 \%)$ & $44(73.3 \%)$ \\
\hline$>7 \%$ & $27(50.9 \%)$ & $18(34.6 \%)$ & $29(64.4 \%)$ & $16(26.7 \%)$ \\
\hline \multicolumn{5}{|l|}{ Control of diabetes } \\
\hline Controlled & $18(33.9 \%)$ & $29(55.8 \%)$ & $13(28.9 \%)$ & $34(56.7 \%)$ \\
\hline Uncontrolled & $35(66.1 \%)$ & $23(44.2 \%)$ & $32(71.1 \%)$ & $26(43.3 \%)$ \\
\hline \multicolumn{5}{|l|}{ No of complication } \\
\hline$<3$ & $26(49.1 \%)$ & $24(46.2 \%)$ & $15(33.3 \%)$ & $35(58.3 \%)$ \\
\hline 3 & $10(18.9 \%)$ & $16(30.8 \%)$ & $12(26.7 \%)$ & $14(23.3 \%)$ \\
\hline$>3$ & $17(32.0 \%)$ & $12(23.0 \%)$ & $18(40.0 \%)$ & $11(18.4 \%)$ \\
\hline
\end{tabular}




\section{Anxiety and depression status by demographic clinical and social variables}

Table 3 reports that the anxiety and depression were observed more among the participants between an age range of 25-54 (66.1\%) for anxiety and 53.3\% for depression. Both these distresses were common in illiterate subjects for both anxiety and depression, unemployed and low-income subjects. Anxiety and depression were also common among the participants with moderate social support, participants with $\mathrm{HbA}_{1 \mathrm{c}}$ $>7 \%$ and uncontrolled diabetic control.

\section{Independent predictors of anxiety and depression among diabetics}

Table 4 shows the prediction of anxiety and depression among diabetic patients using multivariable logistic regression. We observed significant association between individual's anxiety status and unemployment rate $(\phi=0.025)$, individual's depression status and illiteracy rate $(p=0.03)$ and low income per month $(p=0.01)$. The result demonstrated that odds of being diagnosed as having anxiety and depression on HADS were greater among patient who were illiterate $(\mathrm{OR}=1.50,95 \%$ CI 0.92-5.38), unemployed (OR $=7.50,95 \%$ CI 1.29-43.61) and had low income ( $\mathrm{PR}=3.0995 \% \mathrm{CI}$ 0.92-10.36) for individual with anxiety and the patients who were married $(\mathrm{OR}=3.27$ 95\% CI 0.35-30.33), unemployed (OR=14.50 95\% CI 2.34-90.12), retired $(\mathrm{OR}=6.00,95 \% \mathrm{CI} 0.81-44.35) \mathrm{had}$ depression.

\section{Analysis of risk associated with the prevalence of anxiety}

Table 5 shows that the age of the patients was independently associated with the prevalence of anxiety $(p=0.782)$. The patients of 25-54 years were at higher risk $(\mathrm{RR}=1.058)$ with the $\mathrm{OR}=1.120$. There was a strong association with the gender of the patients $(p=0.014)$. It is seen that the males are less likely to be present with anxiety symptoms as compared to females $(\mathrm{OR}=0.261)$ with the relative risk of $(R R=0.532)$. The insulin use was independently associated with the prevalence of anxiety. The result demonstrated an independent association between the prevalence of anxiety. The anxiety is found to be less likely among controlled group ( $\mathrm{OR}=0.408)$.

\section{Table 4: Independent predictors of anxiety and depression among diabetic patients.}

\begin{tabular}{|c|c|c|c|c|}
\hline & \multicolumn{2}{|r|}{ Anxiety } & \multicolumn{2}{|r|}{ Depression } \\
\hline Characteristics & $p$-value & Odd ratio $(95 \% \mathrm{Cl})$ & $p$-value & Odd ratio $(95 \% \mathrm{Cl})$ \\
\hline \multicolumn{5}{|l|}{ Marital status } \\
\hline $\begin{array}{l}\text { Married } \\
\text { Unmarried }\end{array}$ & 0.657 & $0.67(0.12-4.16)$ & 0.215 & $3.27(0.35-30.33)$ \\
\hline \multicolumn{5}{|l|}{ Education level } \\
\hline Illiterate & 0.534 & $1.50(0.42-5.38)$ & 0.000 & $0.03(0.01-0.19)$ \\
\hline Primary school & 0.564 & $1.50(0.38-5.95)$ & 0.043 & $0.17(0.03-0.95)$ \\
\hline Intermediate & 0.890 & $0.91(0.24-3.52)$ & 0.219 & $0.33(0.06-1.92)$ \\
\hline High school & 0.123 & $0.27(0.05-1.42)$ & 0.548 & $2.12(0.17-27.08)$ \\
\hline Diploma & 0.100 & $1.00(0.15-6.78)$ & 0.891 & $1.2(0.09-16.44)$ \\
\hline Graduate & & & & \\
\hline \multicolumn{5}{|l|}{ Occupation } \\
\hline Unemployed & 0.025 & $7.50(1.2943 .608)$ & 0.004 & $14.50(2.34-90.12)$ \\
\hline Employed & 0.321 & $2.36(0.43-12.84)$ & 0.334 & $0.41(0.07-2.51)$ \\
\hline Retired & 0.691 & $1.50(0.20-11.09)$ & 0.079 & $6.00(0.81-44.35)$ \\
\hline Other & & & & \\
\hline \multicolumn{5}{|c|}{ Income per month } \\
\hline$<5,000$ & 0.068 & $3.09(0.92-10.36)$ & 0.000 & $0.01(0.01-0.09)$ \\
\hline $5,000-10,000$ & 0.309 & $1.82(0.57-5.78)$ & 0.180 & $0.14(0.03-0.71)$ \\
\hline $10,000-15,000$ & 0.633 & $1.35(0.39-4.57)$ & 0.879 & $0.86(0.13-5.76)$ \\
\hline$>15,000$ & & & & \\
\hline \multicolumn{5}{|l|}{ Duration } \\
\hline $1-10$ & 0.590 & $1.96(0.17-22.36)$ & 0.009 & $0.25(0.09-0.71)$ \\
\hline $10-20$ & 0.410 & $3.00(0.22-40.93)$ & & \\
\hline$>20$ & & & & \\
\hline \multicolumn{5}{|l|}{ Social support } \\
\hline High & 0.271 & $0.43(0.09-1.94)$ & 0.007 & $0.05(0.01-0.45)$ \\
\hline Moderate & 0.105 & $0.31(0.08-1.28)$ & 0.011 & $0.06(0.01-0.53)$ \\
\hline Low & & & & \\
\hline \multicolumn{5}{|c|}{ No of complication } \\
\hline$<3$ & 0.569 & $0.77(0.30-1.93)$ & 0.011 & $0.29(0.11-0.749)$ \\
\hline 3 & 0.138 & $0.44(0.15-1.30)$ & 0.239 & $0.524(0.18-1.54)$ \\
\hline$>3$ & & & & \\
\hline
\end{tabular}


Table 6 Represents that the of $55-84$ years were less likely to have the symptoms of depression $(\mathrm{OR}=0.476)$ with low risk $(R R=0.0242)$. Male showed lower risk of depression $(\mathrm{RR}=0.373)$ as compared to female with an $\mathrm{OR}=0.167$. The insulin use was independently associated with the prevalence of depression $(p=0.180)$. $\mathrm{HbA}_{1 \mathrm{c}} \%$ of the diabetic patients was strongly associated with the prevalence of depression $(p=0.000)$. The patients with controlled diabetes were less likely to encounter the symptoms of depression.

\section{DISCUSSION}

This study is aimed at identifying the association and the prevalence of anxiety and depression among diabetic patients carried out in the outpatient department in Lifeline hospital. This study showed that both the anxiety and depression are prevalent among the study participants. It shows that $50.48 \%$ of the patients with diabetes showed symptoms of anxiety, while $42.86 \%$ were present with the symptoms of depression. Other study reported depression in $28.5 \%$ of the subjects and anxiety was found in $42.4 \%$ of the subjects. ${ }^{19}$

Logistic regression analysis revealed that the females were more vulnerable to anxiety and depression in this study. Similar to the result anxiety was more common $(p<0.001)$ in females than in males in the study conducted by Mikaliukestiene A et al. ${ }^{19}$ According to Tellez-Zenteno and Cardiel, the risk of depression in female was twice as high as in male. ${ }^{20}$

In this study depression was more common in older patients probably due to higher disease severity, reduced mobility, multiple chronic conditions and reduced social interaction, which as coincidental to the study conducted

\begin{tabular}{|c|c|c|c|c|c|}
\hline & Variables & & $p$-value & Relative risk & Odd ratio $(95 \% \mathrm{Cl})$ \\
\hline Age & No. of patients & Patients \% & 0.782 & 1.058 & \\
\hline $25-54$ & 35 & 51.5 & & & $1.120(0.502-2.494)$ \\
\hline $55-84$ & 18 & 48.6 & & & \\
\hline Gender & & & 0.014 & 0.532 & $0.261(0.115-0.594)$ \\
\hline Male & 22 & 36.7 & & & \\
\hline Female & 31 & 68.9 & & & \\
\hline Insulin use & & & 0.596 & 1.111 & $1.24(0.561-2.740)$ \\
\hline Yes & 21 & 53.8 & & & \\
\hline No & 32 & 48.5 & & & \\
\hline $\mathrm{HbA}_{1 \mathrm{c}} \%$ & & & 0.091 & 0.722 & $0.510(0.233-1.118)$ \\
\hline$<7$ & 26 & 43.3 & & & \\
\hline$>7$ & 27 & 60.0 & & & \\
\hline Control of diabetes & & & 0.025 & 0.635 & $0.408(0.185-0.898)$ \\
\hline Controlled & 18 & 38.3 & & & \\
\hline uncontrolled & 35 & 60.3 & & & \\
\hline
\end{tabular}

\section{Table 6: Risk associated with the prevalence of Depression.}

\begin{tabular}{|c|c|c|c|c|c|}
\hline Variables & & & $p$-value & Relative risk & Odd ratio $(95 \% \mathrm{Cl})$ \\
\hline Age & No. of patients & patients $\%$ & 0.001 & 0.0242 & $0.476(0.104-0.565)$ \\
\hline $25-54$ & 21 & 30.9 & & & \\
\hline $55-84$ & 24 & 64.9 & & & \\
\hline Gender & & & 0.000 & 0.375 & $0.167(0.071-0.391)$ \\
\hline Male & 15 & 25.0 & & & \\
\hline Female & 30 & 66.7 & & & \\
\hline Insulin use & & & 0.180 & 1.354 & $1.726(0.775-3.846)$ \\
\hline Yes & 20 & 51.3 & & & \\
\hline No & 25 & 37.9 & & & \\
\hline $\mathrm{HbA}_{1 \mathrm{c}} \%$ & & & 0.000 & 0.414 & $0.201(0.087-0.463)$ \\
\hline$<7$ & 16 & 26.7 & & & \\
\hline$>7$ & 29 & 64.4 & & & \\
\hline Control of diabetes & & & 0.005 & 0.501 & $0.311(0.137-0.707)$ \\
\hline Controlled & 13 & 27.7 & & & \\
\hline uncontrolled & 32 & 55.2 & & & \\
\hline
\end{tabular}


by Engum et al. ${ }^{21}$ Earlier studies demonstrated that different complications such as neuropathy, retinopathy, nephropathy, cardiovascular diseases result in depressions in diabetic patients. ${ }^{22}$

On contrary anxiety was more common among younger patients in our study, which may be due to lifestyle modification, dietary restriction and use of oral medication or insulin use. Positive association was reported between $\mathrm{HbA}_{1 \mathrm{c}}$ levels, fasting blood glucose and anxiety in studies carried out in the past. ${ }^{23}$ Our study showed that insulin did not affect the status of anxiety and depression, similar to the report presented in previous studies. ${ }^{24,25}$

Identifying mental disorders and their associated factors among diabetic patients will be of great help for the health care professionals in the management of such disorders to provide a better quality of life to the patients with anxiety and depression. The main limitation of the study was small sample size. The hospital Anxiety and depression scale (HADS) is limited tool for screening anxiety and depression and it should be confirmed only with clinical diagnosis. An effective strategy is recommended for preventing anxiety and depression

\section{CONCLUSION}

A significant association between anxiety and depression is seen among the patients with diabetes mellitus, which was higher in female than in males. Most of the patients with diabetes had developed moderate or severe anxiety or depression.

The common risk factors for anxiety and depression within patients were low income, age, education level, employment status, control of diabetes. The study finding suggests that the anxiety and depression needs to be screened and taken into consideration to diagnose early and treat promptly to improve the outcome in such patient. Additionally, health education and awareness programs should be made for the awareness of relationship between diabetes mellitus and depression and anxiety. Counseling and appropriate medication can be initiated to reduce the future complications.

\section{ACKNOWLEDGEMENT}

I would like to express my deepest and special gratitude to the staff members of LIFE LINE HOSPITAL for their kind co-operation, help and encouragement by providing all the requisite data genuinely for the successful completion of the study. And a special thanks to all those who have always helped in a long way for my research project to complete successfully.

\section{CONFLICT OF INTEREST}

No conflict of interest to declare.

\section{ABBREVIATIONS}

DM1: Diabetes mellitus Type 1; DM2: Diabetes mellitus Type 2; NCDs: Non-communicable diseases; SPSS: Statistical Package for the Social Sciences; HPA-axis: Hypothalamus-Pituitary-Adrenal axis; SNS: Sympathetic Nervous System; HADS: Hospital anxiety and depression scale.

\section{SUMMARY}

A strong association exist between psychological disorders such as depression and anxiety with diabetes mellitus although it often remains undiagnosed and unidentified on clinical grounds which further aids to the medical complications in patients leading to increased morbidity and mortality. Timely screening and early diagnosis ameliorate the outcome.

\section{REFERENCES}

1. India State-Level Disease Burden Initiative Diabetes Collaborators. The increasing burden of diabetes and variations among the states of India: The Global Burden of Disease Study 1990-2016. Lancet Glob Health. 2018;6(12):e352-62. Cited in PubMed; PMID 30219315.

2. Sarwar N, Gao P, Seshasai SR, Gobin R, Kaptoge S, DiAngelantonio E. et al. Diabetes mellitus, fasting blood glucose concentration and risk of vascular disease: A collaborative meta-analysis of 102 prospective studies. Lancet. 2010;375(9733):2215-22.

3. Cho NH, Shaw JE, Karuranga S, Huang Y, DaRocha FJD, Ohlrogge, et al. IDF Diabetes Atlas: Global estimate of diabetes prevalence for 2017 and projections for 2045. Diabetes Research and Clinical Practice. 2018;138:271-81.

4. World Health Organization. Geneva: Global report on diabetes. 2016. Avialable from:https://apps.who.int/iris/bitstream/handle/10665/204871/9789241565257_ eng.pdf;jsessionid=9B1EF12175581E7DAF7F2EA7A6C892B5? sequence=1.

5. Gemeay EM, Moawed SA, Mansour EA, Ebrahiem NE, Moussa IM, Nadrah WO. The association diabetes and depression. Saudi Med Journal. 2015;36(10):1210-5.

6. EIMahalli AA. Prevalence and predictiors of depression among type 2 diabetes mellitus outpatients in Estern Province, Saudi Arabia. Int J Health Sci. 2015;9(2):119-26.

7. Al-Shehri SZ, Sabra AA, Taha AZ, Khamis AH, Hafez AS. Depression and Anxiety among Males Attending Primary Health Care Centers, Eastern Saudi Arabia: Prevalence and Predictors. Life Science Journal. 2012;9(3):128-33.

8. Chen S, Zhang Q, Dai G, Hu J, Zhu C, Su L, et al. Association of depression with pre-diabetes, undiagnosed diabetes and previously diagnosed diabetes: A Meta-analysis. Endocrine. 2016;53(1):35-46.

9. Grover S, Dutt A, Avasthi A. An overview of Indian research in depression. Indian Journal of Psychiatry. 2010;52(7):178-88.

10. Roy T, Lloyd CE. Epidemiology of depression and diabetes: A systematic review. J Affect Disord. 2012;142(Suppl):8-21. 
11. Grigsby AB, Anderson RJ, Freedland KE, Clouse RE, Lustman PJ. Prevalence of anxiety in adults with diabetes: A systematic review. J Psychosom Res. 2002;53(6):1053-60.

12. Collins MM, Corcoran P, Perry IJ. Anxiety and depression symptoms in patients with diabetes. Diabet Med. 2009;26(2):153-61.

13. Chrousos GP. Stress and disorders of the stress system. Nat Rev Endocrinol. 2009;5(7):374-81.

14. Kyrou I, Tsigos C. Stress hormones: Physiological stress and regulation of metabolism. Curr Opin Pharmacol. 2009;9(6):787-93.

15. Wang X, Bao W, Liu J, Ouyang YY, Wang D, Rong S, et al. Inflammatory markers and risk of type 2 diabetes: Asystematic review and meta-analysis. Diabetes Care. 2013;36(1):166-75.

16. Korczak DJ, Pereira S, Koulajian K, Matejcek A, Giacca A. Type 1 diabetes mellitus and major depressive disorder: Evidence for a biological link. Diabetologia. 2011;54(10):2483-93.

17. Karam EG, Mneimneh ZN, Fayyad JA, Dimassi H, Karam AN, Nasser SC. Lifetime prevalence of mental health diorders: First onsent, treatment and exposure to war- the Lebanon study. Plos Med. 2008;5(4):61.

18. Demyttenaere K, Bruffaerts R, Posada-Villa J, Gasquet I, Kovess V, Lepine $\mathrm{JP}$, et al. Prevalence, severity and unmet need for treatment of mental disorders in the World Health Organization World Metal Health Surveys. JAMA 2004;91(21):2581-90.
19. Mikaliukestiene A, Zagminas K, Juozulynas A, Narkauskaite L, Salyga J, Jankauskiene $\mathrm{K}$, et al. Prevalence and determinants of anxiety and depression symptoms in patients with type 2 diabetes in Lithuania. Med Sci Monit. 2014;20:182-90

20. Tellez-Zenteno JF, Cardiel MH. Risk factors associated with depression in patients with type 2 diabetes mellitus. Arch Med Res. 2002;33(1):53-60.

21. Engum A, Mykeltun A, Midthjell K, et al. Depression and diabetes: $A$ large population-based study of sociodemographic, lifestyle and clinical factors associated with depression in type 1 and type 2 diabetes. Diabetes Care. 2005;28(8):1904-9.

22. Karlson B, Agardh CD. Burden of illness, metabolic control and complications in relation to depressive symptoms in IDDM patients. Diabet Med. 1997;14(12):1066-72.

23. Pouwer F. Should we screen for emotional distress in type 2 diabetes mellitus?. NatRev Endocrinol. 2009;5(12):66-71.

24. Papelbaum M, Moreira RO, Coutinho W, Kupfer R, Zagury L, Freitas S, et al. Depression, glycemic control and type 2 diabetes. Diabetol Metab Syndr. 2011;3(1):26.

25. Joseph N, Unnikrishnan B, Raghavendra BYP, Kotian MS, Nelliyanil M Proportion of depression and its determinants among type 2 diabetes mellitus patients in various tertiary care hospitals in Mangalore city of South India. Indian J Endocrinol Metab. 2013;17(4):681-8. 